\title{
Chloroform fraction of Scutellaria barbata D. Don inhibits the growth of colorectal cancer cells by activating miR-34a
}

\author{
LING ZHANG $^{1,2}$, YI FANG ${ }^{1,2}$, JIAN-YU FENG ${ }^{1,2}$, QIAO-YAN CAI ${ }^{1,2}$, \\ LI-HUI WEI ${ }^{1,2}$, SHAN LIN ${ }^{1,2}$ and JUN PENG ${ }^{1,2}$ \\ ${ }^{1}$ Academy of Integrative Medicine, ${ }^{2}$ Fujian Key Laboratory of Integrative Medicine on Geriatrics, \\ Fujian University of Traditional Chinese Medicine, Fuzhou, Fujian 350122, P.R. China
}

Received October 26, 2016; Accepted April 19, 2017

DOI: $10.3892 /$ or.2017.5625

\begin{abstract}
Scutellaria barbata D. Don (SB) is a well known formula in traditional Chinese medicine, which exhibits potent anticancer effects on various cancers. Many miRNAs play crucial roles in the regulation of cancer, for instance, miR-34a functions as a tumor suppressor, and is often downregulated during cancer. In this study, we investigated the role of ECSB in suppressing the growth of human colon cancer HCT-8 cells, and whether this is mediated by regulation of miR-34a and its downstream target genes, using real-time PCR and western blot analysis. ECSB treatment significantly inhibited the proliferation of HCT-8 cells and promoted apoptosis in a dosedependent manner. In addition, ECSB treatment significantly increased the level of miR-34a expression and decreased the levels of Bcl-2, Notch1/2 and Jagged1 expression. Furthermore, knockdown of miR-34a expression through transfection of anti-miR-34a oligonucleotide was significantly reversed by ECSB treatment. Likewise, knockdown of miR-34a resulted in significant upregulation of Bcl-2, Notch1/2 and Jagged1 expression, which was reversed following ECSB treatment. Therefore, this study reveals that ECSB inhibited cancer cell growth via promoting apoptosis and inhibiting proliferation, through regulation of miR-34a. These findings further support the use of ECSB as an effective therapeutic agent against colon cancer.
\end{abstract}

Correspondence to: Dr Jun Peng, Academy of Integrative Medicine, Fujian University of Traditional Chinese Medicine, Fuzhou, Fujian 350122, P.R. China

E-mail: pjunlab@hotmail.com

Abbreviations: CRC, colorectal cancer; SB, Scutellaria barbata D. Don; ECSB, chloroform fraction of Scutellaria barbata D. Don; TCM, traditional Chinese medicine; MTT, 3-(4,5-dimethylthiazol2-yl)-2,5-diphenyltetrazolium bromide; DMSO, dimethyl sulfoxide miR-34a, microRNA-34a; AMO-34a, anti-miR-34a oligonucleotide

Key words: chloroform fraction of Scutellaria barbata D. Don, colorectal cancer, apoptosis, proliferation, miR-34a, Notch1/2, Jagged1, Bcl-2

\section{Introduction}

Colorectal cancer (CRC) is one of the most common types of cancers in both men and women, worldwide (1). Current treatment of CRC usually involve surgery; however, $\sim 20 \%$ of patients who undergo surgery ultimately develop metastases over the follow-up period (2). Treatment using 5-fluorouracil (5-FU)-based regimen has also been used as a standard therapeutic approach for CRC patients. However, due to drug resistance and related side-effects, the five-year survival rate is an unsatisfactory $64.9 \%$ (3). Recently, the use of traditional Chinese medicine (TCM) formulas consisting of various natural compounds, have been associated with potent anticancer therapeutic effects with fewer side-effects.

Scutellaria barbata D. Don (SB) is a well-known TCM formula with strong anticancer effects against various cancers including CRC (4-7). We had previously demonstrated that the ethanol extract of SB inhibited colorectal cancer growth in vivo and in vitro via promoting apoptosis, while suppressing proliferation and tumor angiogenesis (7-10). Furthermore, we determined that of the four polar fractions (petroleum ether, chloroform, ethyl acetate and N-butanol) of SB, the chloroform fraction of SB (ECSB) exhibited the most potent inhibitory effect on colorectal cancer growth, via upregulation of pro-apoptotic $\mathrm{Bax} / \mathrm{Bcl}-2$ ratio and downregulation of pro-proliferative cyclin D1 and cyclin-dependent kinase 4 (11). However, the potential mechanism of ECSB exerting its anticancer effects is still not fully understood.

miRNAs are commonly involved in the post-transcriptional control of gene expression by targeting mRNAs for cleavage or translational suppression (12). Over $60 \%$ of all protein coding genes in humans are predicted to be regulated by miRNAs. Dysregulation of miRNAs is often implicated as a precursor to various human diseases including cancer $(13,14)$. Among these, miR-34a has been implicated as a tumor suppressor in numerous cancers (15). Recently, several protein-coding genes have been identified to be directly targeted by miR-34a, including Bcl-2, SIRT1, Notch1/2, Jagged1, CDK4/6, cyclin E2, cyclin D1, E2F, c-Myc and c-MET (16-18). Activation of miR-34 results in the downregulation of its downstream target genes, which in turn regulates various cellular processes such as cell proliferation, apoptosis, senescence, migration and invasion (18-21). For example, miR-34a activation has been 
associated with downregulation of Notch signaling in colon cancer stem cells (22). Therefore, this study was conducted to examine whether ECSB inhibited the growth of HCT-8 cells through regulating miR-34a and its downstream target genes.

\section{Materials and methods}

Material andreagents. RPMI-1640 medium, fetal bovine serum (FBS), penicillin-streptomycin, trypsin-EDTA, 3-(4,5-dimethylthiazol-2-yl)-2, 5-diphenyltetrazolium bromide (MTT) and TRIzol reagent were obtained from Invitrogen (Invitrogen Life Technologies, Carlsbad, CA, USA). Bcl-2 (no. 3498), Jagged1 (no. 2155), Notch1 (no. 2495), Notch2 (no. 2420) and horseradish peroxidase (HRP)-conjugated secondary antibodies (anti-rabbit IgG, no. 7074) were purchased from Cell Signaling Technology (Beverly, MA, USA). Fluorescein isothiocyanate (FITC)-conjugated Annexin V apoptosis detection kit was provided by Becton-Dickinson (San Jose, CA, USA). All the other chemicals, unless otherwise stated, were obtained from Sigma-Aldrich (St. Louis, MO, USA).

Preparation of the SB extract. SB was purchased from Guo Yi Tang Chinese Herbal Medicine Store (Fujian, China). Different polar fractions of SB were prepared as previously described (11). The chloroform fraction of SB (ECSB) was dissolved in $100 \%$ dimethylsulfoxide (DMSO) to a stock concentration of $200 \mathrm{mg} / \mathrm{ml}$ and stored at $-20^{\circ} \mathrm{C}$. The working concentration of ECSB was obtained by diluting the stock solution in the cell culture medium. The final concentration of DMSO in the cell culture medium was $\leq 0.25 \%$ for all experiments.

Cell culture. Human colon cancer HCT-8 cells were obtained from the Nanjing KeyGen Biotech. Co. Ltd. (Nanjing, Jiangsu, China). HCT-8 cells were cultured in RPMI-1640 medium, supplemented with $10 \%$ fetal bovine serum, $100 \mathrm{U} / \mathrm{ml}$ penicillin and $100 \mathrm{mg} / \mathrm{ml}$ streptomycin in a $37^{\circ} \mathrm{C}$ humidified incubator supplemented with $5 \% \mathrm{CO}_{2}$.

Evaluation of cell viability using MTT assay. Cell viability was assessed using MTT colorimetric assay. HCT- 8 cells were seeded into 96-well plates at a density of $1 \times 10^{5}$ cells/ $\mathrm{ml}$ and treated with various concentrations of ECSB for 24 or $48 \mathrm{~h}$, respectively. Following removal of cell culture medium, $100 \mu \mathrm{l}$ of MTT $(0.5 \mathrm{mg} / \mathrm{ml})$ was added to each well and cells were incubated for an additional $4 \mathrm{~h}$ at $37^{\circ} \mathrm{C}$. Subsequently, the MTT formazan precipitate was dissolved in $100 \mu \mathrm{l}$ of DMSO and the resulting absorbance was measured at $570 \mathrm{~nm}$ using an ELISA plate reader (model ELX800; BioTek, Winooski, VT, USA). The cell viability was determined using the formula: Cell viability $(\%)=$ sample optical density (OD)/ control OD x 100.

Observation of morphologic changes. HCT-8 cells were seeded into 6-well plates at a density of $2 \times 10^{5}$ cells $/ \mathrm{ml}$ and treated with various concentrations of ECSB for $48 \mathrm{~h}$. Cell morphology was observed using a phase-contrast microscope (Olympus, Tokyo, Japan). Photographs were taken at a magnification of $\mathrm{x} 200$.
Colony formation. HCT-8 cells were seeded into 6-well plates at a density of $2 \times 10^{5}$ cells $/ \mathrm{ml}$ and treated with various concentrations of ECSB for $48 \mathrm{~h}$. Subsequently, cells were harvested and diluted in fresh medium without ECSB, and reseeded at a density of 1,000 cells/well. The cell culture medium was replaced with fresh medium every three days. Following 12 days, cells were fixed with $10 \%$ formaldehyde, stained with $0.01 \%$ crystal violet and counted. Cell survival rate was calculated by normalizing the survival rate of control cells as $100 \%$.

Detection of apoptosis. After incubation with various concentrations of ECSB for $48 \mathrm{~h}, \mathrm{HCT}-8$ cell apoptosis was determined by flow cytometry analysis using a fluorescence-activated cell sorting (FACS) caliber (Becton-Dickinson, CA, USA) and Annexin V-FITC/PI kit (Becton-Dickinson). Staining was performed according to the manufacturer's instructions. Annexin V-positive and PI-negative cells indicated presence of early apoptosis, whereas both Annexin V-positive and PI-positive cells indicated late apoptosis.

Small interfering RNAs. Anti-miR-34a oligonucleotide and scrambled oligonucleotide (used as negative control) were obtained from Invitrogen (Invitrogen Life Technologies). Transfection was performed using RNAiMAX kit (Invitrogen Life Technologies) according to the manufacturer's instructions. After transfection for $6 \mathrm{~h}, \mathrm{HCT}-8$ cells were treated with ECSB $(150 \mu \mathrm{g} / \mathrm{ml})$ for $48 \mathrm{~h}$ and total RNAs and protein were extracted for real-time PCR and western blot analysis.

RNA extraction and real-time PCR analysis. Total RNA was isolated using TRIzol reagent (Invitrogen Life Technologies). First-strand cDNA was generated by reverse transcription of $2 \mu \mathrm{g}$ total RNA using Oligo (dT) or special RT-miR-34a primer and SuperScript II reverse transcriptase according to the manufacturer's instructions. The mRNA levels of miR-34a, Bcl-2, Notch1, Notch2 and Jagged1 was determined with real-time PCR analysis using SYBR Premix Ex Taq II (Takara, Dalian, China) and ABI 7500 Fast PCR system, according to the manufacturer's instructions. U6 and $\mathrm{B}_{2} \mathrm{M}$ were used as the internal controls for miR-34a and other genes, respectively. The mRNA expression was quantified by comparing the cycle threshold $(\mathrm{Ct})$ values. The experimental data were analyzed using the $2^{-\Delta \Delta C t}$ method. All experiments were performed in triplicate.

Western blot analysis. HCT-8 cells were lysed with mammalian cell lysis buffer (Pierce Chemical Co., Rockford, IL, USA) containing protease and phosphatase inhibitor. The protein concentrations were quantified using the bicinchoninic acid protein assay (Pierce Chemical Co.), and $50 \mu \mathrm{g}$ of proteins were separated on $12 \%$ SDS-PAGE gels and transferred onto PVDF membranes (Millipore Corp., Billerica, MA, USA). The membranes were blocked with $5 \%$ non-fat dry milk and probed with primary antibodies against Bcl-2, Notch1, Notch2, Jagged1 and GAPDH $(1: 1,000)$ overnight at $4^{\circ} \mathrm{C}$. The membranes were washed three times with Tris-buffered saline with Tween-20 (TBST) prior to incubation with the appropriate HRP-conjugated secondary antibodies for $1 \mathrm{~h}$ at room temperature. Following washing in TBST, the protein bands 
A

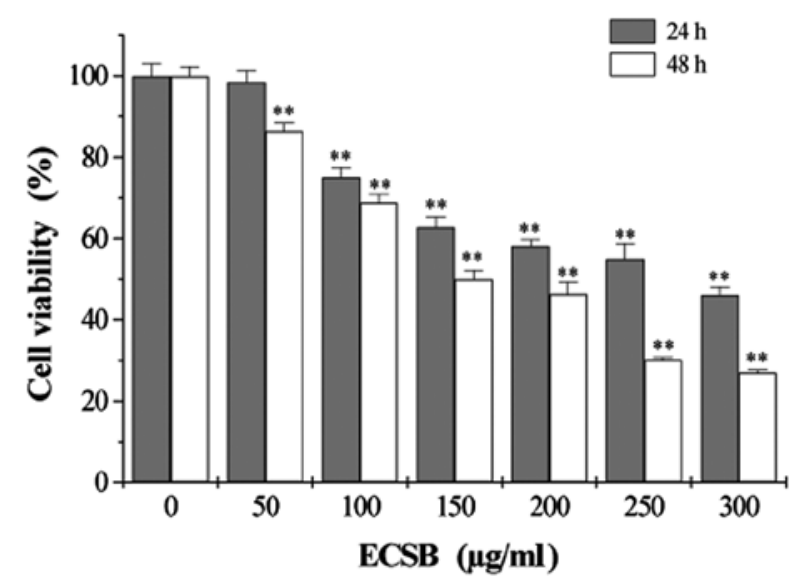

B

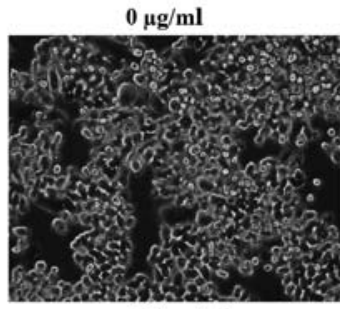

$150 \mu \mathrm{g} / \mathrm{ml}$
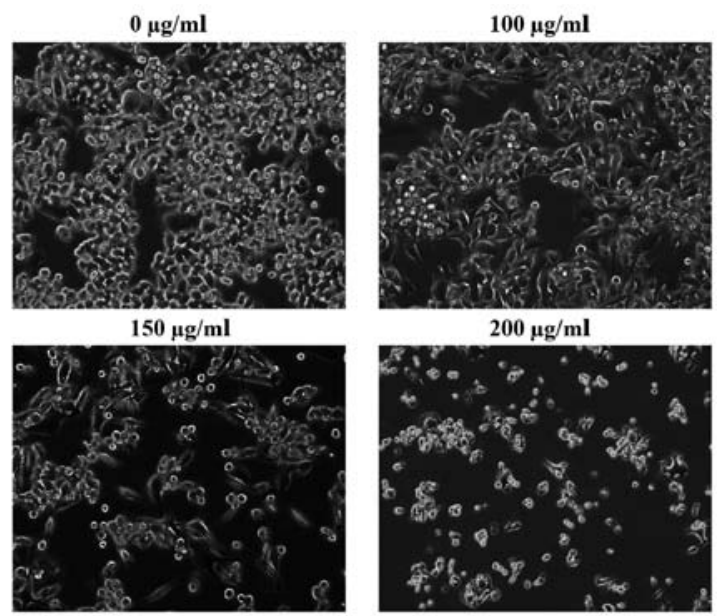

$200 \mu \mathrm{g} / \mathrm{ml}$

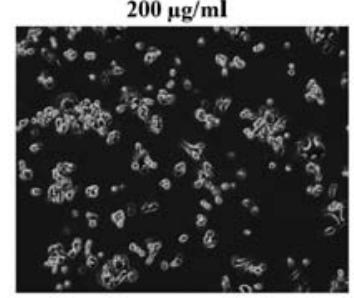

Figure 1. Effect of ECSB on the viability of HCT-8 cells. (A) HCT-8 cell viability was determined by MTT assay following treatment with the indicated concentrations of ECSB for 24 or $48 \mathrm{~h}$, respectively. Data were normalized to the viability of untreated control cells. Data are expressed as the mean \pm standard deviation from three independent experiments. ${ }^{* *} \mathrm{P}<0.01$, vs. untreated control cells. (B) HCT-8 cell morphology was determined via phase-contrast microscopy following treatment with the indicated concentrations of ECSB for $48 \mathrm{~h}$. ECSB, chloroform fraction of Scutellaria barbata D. Don.

were detected using enhanced chemiluminescence. GAPDH was used as an internal control.

Statistical analysis. Each experiment was performed three times independently. Data were expressed as mean \pm standard deviation. Statistical analysis was analyzed using SPSS package for Windows (version 13.0; SPSS Inc., Chicago, IL, USA) by the Student's t-test. P-values $<0.05$ were considered as statistically significant.

\section{Results}

ECSB inhibits the growth of HCT-8 cells. We first examined the effect of ECSB on HCT-8 cell viability using MTT assay. ECSB treatment significantly inhibited cell viability in a dose- and time-dependent manner (Fig. 1A). After 24 h, ECSB treatment decreased HCT-8 cell viability from 98.4 to $36.7 \%$. Similarly, after $48 \mathrm{~h}$, ECSB treatment decreased HCT-8 cell viability from 86.4 to $23.5 \%$. We further examined the effect
A
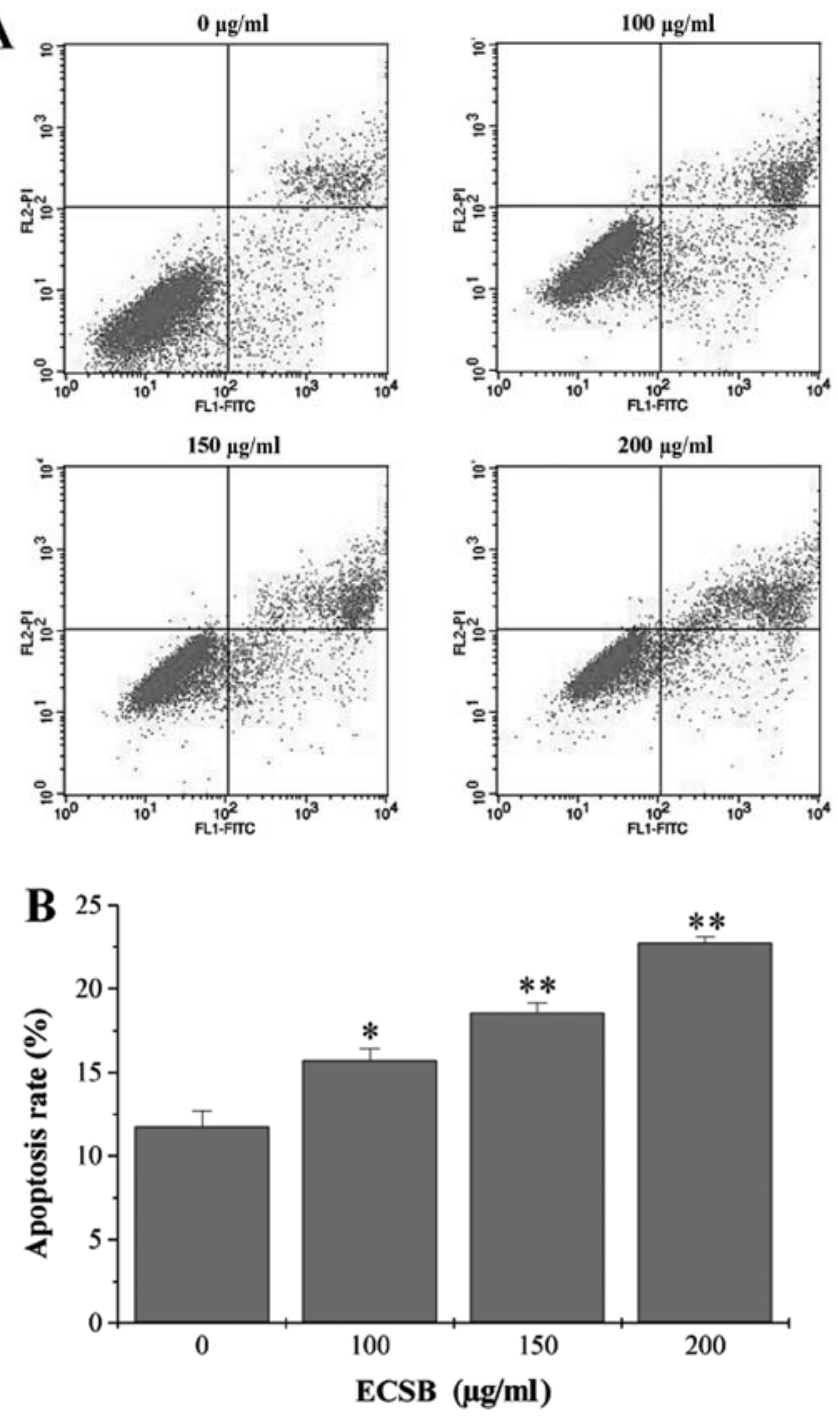

Figure 2. Effect of ECSB on apoptosis of HCT-8 cells. (A) FACS analysis of Annexin V/PI stained HCT-8 cells following treatment with the indicated concentrations of ECSB for $48 \mathrm{~h}$. (B) Quantification of FACS analysis. Data are expressed as the mean \pm standard deviation from three independent experiments. ${ }^{*} \mathrm{P}<0.05 ;{ }^{* *} \mathrm{P}<0.01$, vs. untreated control cells. ECSB, chloroform fraction of Scutellaria barbata D. Don; FACS, fluorescence-activated cell sorting; PI, propium iodide; FITC, fluorescein isothiocyanate.

of ECSB on HCT-8 cell morphology using phase-contrast microscopy. Untreated control cells appeared healthy and had a high rate of confluence, whereas ECSB treatment significantly decreased the confluence and state of HCT- 8 cells, in a dose-dependent manner (Fig. 1B). Moreover, ECSB treatment resulted in distinctive rounding of cells, indicative of cellular apoptosis. Taken together, these data revealed that ECSB significantly inhibited the growth of HCT- 8 cells.

ECSB induces apoptosis and suppresses proliferation in HCT-8 cells. We next examined whether ECSB inhibited cell growth through inducing cell apoptosis. HCT-8 cells were stained with Annexin V-FITC/PI and analyzed using flow cytometry analysis (Fig. 2). Following treatment with $0,100,150$ and $200 \mu \mathrm{g} / \mathrm{ml} \mathrm{ECSB}$, the percentage of cells undergoing either early or late apoptosis were 10.42, 16.68, 19.46 and $23.25 \%$, respectively, which demonstrated that 
A
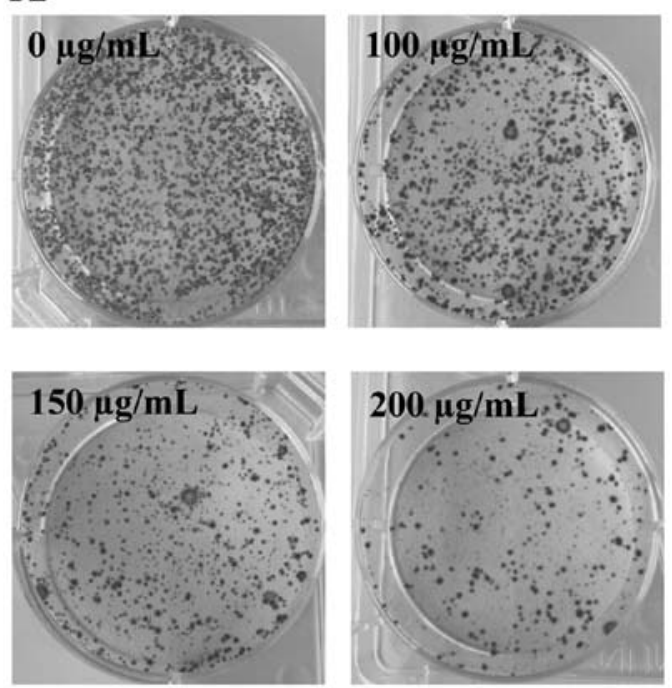

B

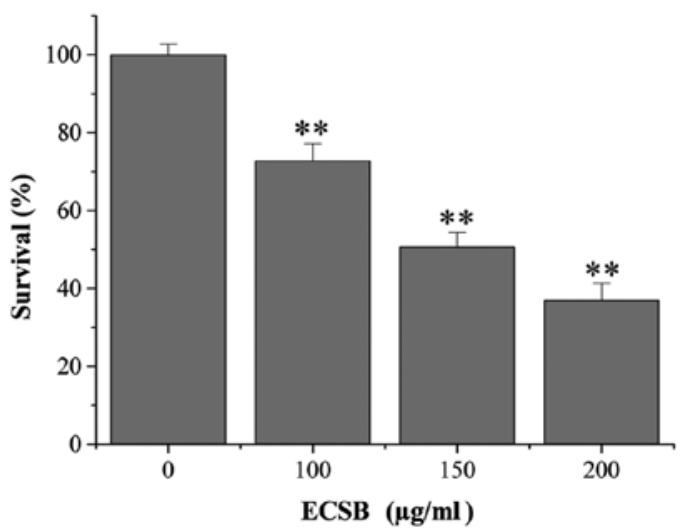

Figure 3. Effect of ECSB on the proliferation of HCT-8 cells. (A) Proliferation of HCT- 8 cells was determined by colony formation assay following treatment with the indicated concentrations of ECSB for $48 \mathrm{~h}$. (B) Quantification of colony formation assay. Data are expressed as the mean \pm standard deviation from three independent experiments. ${ }^{* *} \mathrm{P}<0.01$, vs. untreated control cells. ECSB, chloroform fraction of Scutellaria barbata D. Don.

ECSB promoted HCT-8 cell apoptosis in a dose-dependent manner. Furthermore, we performed colony formation assays to determine the proliferation of HCT- 8 cells following ECSB treatment. Treatment with 100, 150 and $200 \mu \mathrm{g} / \mathrm{ml} \mathrm{ECSB}$ for $48 \mathrm{~h}$ significantly decreased the survival rate of HCT-8 cells by $27.13,49.24$ and $62.96 \%$, respectively $(\mathrm{P}<0.05)$, which demonstrated that ECSB inhibited the proliferation of HCT- 8 cells in a dose-dependent manner (Fig. 3).

ECSB enhances miR-34a expression and decreases its downstream target genes in HCT-8. miR-34a is a member of the miR-34 family which functions as a tumor suppressor in numerous cancers including colon cancer, through inhibition of the genes involved in multiple oncogenic signaling pathways. In addition, genes which are involved in cancer cell growth, such as Bcl-2, Notch1, Notch2 and Jagged1 are candidate target genes of miR-34a. We therefore examined whether ECSB suppresses cancer cell growth through regulation of miR-34a, using real-time PCR analysis. ECSB treatment $(150 \mu \mathrm{g} / \mathrm{ml})$
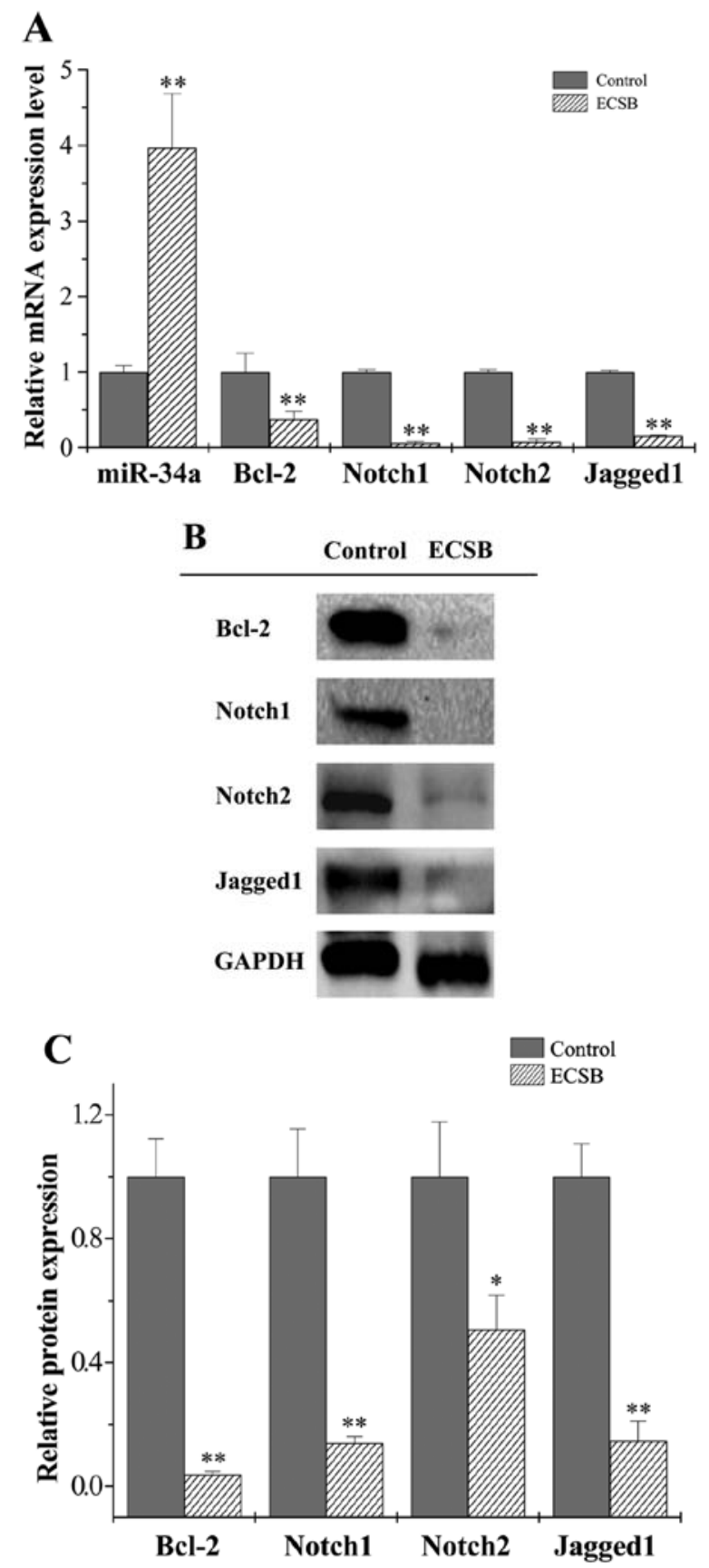

Figure 4. Effect of ECSB on the expression of miR-34a and its downstream target genes in HCT-8 cells. (A) The mRNA expression of miR-34a, Bcl-2, Notch1/2 and Jagged 1 in HCT-8 cells following treatment with $150 \mu \mathrm{g} / \mathrm{ml}$ ECSB for $48 \mathrm{~h}$ were determined by real-time PCR analysis. (B) The protein expression of Bcl-2, Notch $1 / 2$ and Jagged 1 in HCT- 8 cells following treatment with $150 \mu \mathrm{g} / \mathrm{ml}$ ECSB for $48 \mathrm{~h}$ were determined by western blot analysis. (C) Relative densitometric analysis of western blotting. ${ }^{*} \mathrm{P}<0.05 ;{ }^{* *} \mathrm{P}<0.01$, vs. untreated control cells. Images are representative of three independent experiments. ECSB, chloroform fraction of Scutellaria barbata D. Don.

for $48 \mathrm{~h}$ significantly increased the level of miR-34a mRNA expression in HCT-8 cells (Fig. 4A). Furthermore, ECSB treatment also significantly decreased both the mRNA and protein expression levels of miR-34a target genes Bcl-2, Notch1/2 and Jagged1 (Fig. 4). These results suggest that the inhibitory effect of ECSB on cancer cell growth is likely mediated by upregulation of miR-34a expression and the inhibition of its downstream target genes. 
A
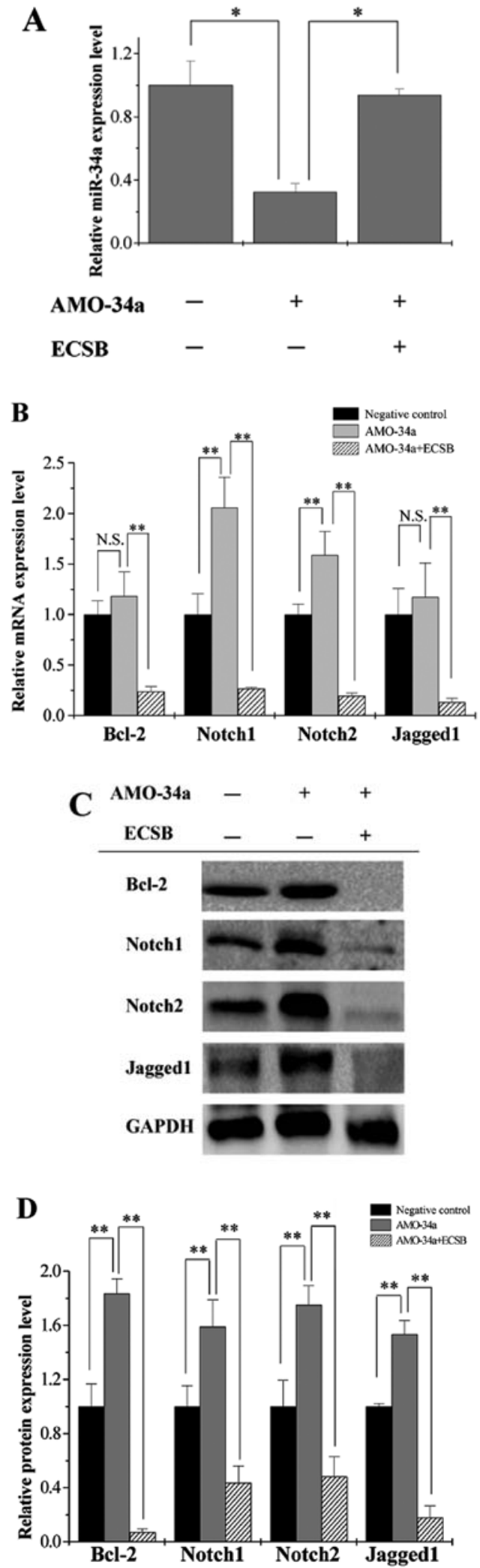

Figure 5. Effect of ECSB on the expression of miR-34a, Bcl-2, Jagged1 and Notch $1 / 2$ in AMO-34a transfected HCT- 8 cells. HCT- 8 cells were treated with the combination of ECSB and AMO-34a comparing to AMO-34a only and a scrambled oligonucleotide was used as the negative control (A) The expression of miR-34a was determined by real-time PCR analysis in the above three groups. (B and C) The expression of Bcl-2, Jagged1 and Notch $1 / 2$ was determined by real-time PCR and western blot analysis in the above three groups. (D) Relative densitometric analysis of western blotting. ${ }^{*} \mathrm{P}<0.05 ;{ }^{* *} \mathrm{P}<0.01$. Images are representative of three independent experiments. ECSB, chloroform fraction of Scutellaria barbata D. Don; AMO-34a, anti-miR-34a oligonucleotide.
ECSB suppresses cancer cell growth through directly targeting miR-34a and downregulating its downstream target genes. To further verify that ECSB inhibited cancer cell growth through directly regulating miR-34a and its downstream target genes (Bcl-2, Notch1, Notch2 and Jagged1), we treated HCT- 8 cells with the combination of ECSB and antimiR-34a oligonucleotide (AMO-34a) comparing to AMO-34a only and a scrambled oligonucleotide was used as the negative control. Expression of miR-34a was significantly decreased following transfection of AMO-34a, which was rescued by ECSB treatment (Fig. 5A), suggesting that ECSB can directly mediate the expression of miR-34a. We next examined the mRNA and protein expression of miR-34a downstream target genes following transfection of AMO-34a in HCT-8 cells. The mRNA expression of Notch $1 / 2$, but not Bcl-2 or Jagged1 was significantly upregulated whereas the protein expression of Notch1/2, Bcl-2 and Jagged1 was significantly upregulated following transfection of AMO-34a in HCT-8 cells. However, following co-treatment with ECSB, the expression of Notch1, Notch2, Bcl-2 and Jagged 1 was drastically decreased compared to AMO-34a transfected cells (Fig. 5B-D). Collectively, these findings reveal that ECSB-induced suppression of cancer cell growth via directly targeting miR-34a and downregulating its downstream target genes.

\section{Discussion}

The underlying mechanisms of colorectal cancer are complex and involve a cascade of signaling pathways, including p53, PI3K, RAS, MAPK, Wnt/ק-catenin pathways, and EMT transcription factors (23). The recent emergence of systems biology have revealed that a wide range of components used in TCM exhibit potent anticancer effects (24). SB is known for its anti-inflammatory and antitumor effects, and is often used in TCM for the treatment of colon cancer. We had previously demonstrated that SB suppressed tumor angiogenesis via inhibition of hedgehog pathway in a mouse model of colorectal cancer; and induced G1/S arrest via modulation of p53 and Akt pathways in human colon carcinoma cells $(8,9)$. In addition, SB inhibited colorectal cancer growth and promoted cell apoptosis via suppression of multiple signaling pathways (7).

Recently, the role of miRNAs in the regulation of various oncogenic signaling pathways has received significant attention. For instance, Pien Tze Huang (PZH) inhibited metastasis of human colon cancer cells via regulation of TGF- $\beta 1 / \mathrm{ZEB} /$ miR-200 signaling network (25). Similarly, Hedyotis diffusa plus Scutellaria barbata promoted bladder cancer cell apoptosis through downregulation of miR-155 expression and inhibition of Akt signaling (26). In this study, we demonstrated that ECSB significantly inhibited the growth of HCT-8 colon cancer cells by suppressing cell proliferation and promoting cell apoptosis. Notably, we revealed that the expression of miR-34a was significantly increased following ECSB treatment, suggesting that the inhibitory effect of ECSB on cancer cell growth is likely mediated by the upregulation of miR-34a.

Notch signaling pathway is involved in a variety of cellular processes, such as cell proliferation, apoptosis, migration, invasion and tumor angiogenesis (27), which is activated when a ligand (DLL or Jagged) interacts with a Notch receptor, 
resulting in the cleavage of Notch and subsequent releases the Notch intracellular domain (NICD) into the nucleus. The NICD acts as a transcription factor to regulate the expression of Notch target genes, including Jagged. Consequently, NotchJagged signaling forms a positive feedback loop in the cells (28). Recent studies have shown that both Notch1/2 receptors and its ligand Jagged1 are direct downstream targets of miR-34a, which are downregulated following miR-34a activation (29). The anti-apoptotic protein Bcl-2, which was triggered to induce cell apoptosis via the activation of Notch signaling in cancer, is other downstream target gene of miR-34a $(30,31)$. Furthermore, the increase in miR-34a expression could also induce apoptosis and inhibit cancer cell proliferation $(16,32)$. These observations correspond with this study, which showed that ECSB-induced suppression of cancer cell growth is mediated by the activation of miR-34a and downregulation of Notch1/2, Jagged and Bcl-2. Moreover, previous studies have shown that the drugs genistein and rhamnetin could also suppress cancer cell growth via activation of miR-34a and inhibition of Notch signaling pathway $(33,34)$.

miR-34a is transcriptionally induced by the tumor suppressor p53. It has been proved that the interaction of p53 and miR-34a is disrupted in various cancer cells (35). Our previous study indicated that SB can induce the proliferation of human colon carcinoma cells via modulation of p53 (8). Therefore, ECSB may directly mediate elevated expression of miR-34a via upregulation of p53. In addition, there is evidence that aberrant $\mathrm{CpG}$ methylation of $\mathrm{miR}-34$ a promoter can result in reduced miR-34a expression (36). However, the mechanism whether ECSB is able to reverse hypermethylation of miR-34a needs to be further explore.

In conclusion, we demonstrated for the first time that ECSB inhibited colorectal cancer growth in HCT- 8 cells via promotion of cell apoptosis and inhibition of cell proliferation, which was mediated by activation of miR-34a and likely suppression of Notch signaling pathway. Our findings also implicate ECSB as an effective and promising therapeutic agent for the treatment of CRC.

\section{Acknowledgements}

This study was sponsored by Fujian Province Natural Science Foundation (2015J01687) and the Youth Science Foundation of Fujian Provincial Health Department (2014-2-29).

\section{References}

1. Torre LA, Bray F, Siegel RL, Ferlay J, Lortet-Tieulent J and Jemal A: Global cancer statistics, 2012. CA Cancer J Clin 65: $87-108,2015$

2. Cekaite L, Eide PW, Lind GE, Skotheim RI and Lothe RA: MicroRNAs as growth regulators, their function and biomarker status in colorectal cancer. Oncotarget 7: 6476-6505, 2016.

3. Siegel R, Desantis C and Jemal A: Colorectal cancer statistics, 2014. CA Cancer J Clin 64: 104-117, 2014.

4. Yang J, Yang G, Hou G, Liu Q, Hu W, Zhao PU and He YI: Scutellaria barbata D. Don polysaccharides inhibit the growth of Calu-3 xenograft tumors via suppression of the HER 2 pathway and angiogenesis. Oncol Lett 9: 2721-2725, 2015.

5. Kim KW, Jin UH, Kim DI, Lee TK, Kim MS, Oh MJ, Kim MS, Kwon DY, Lee YC and Kim CH: Antiproliferative effect of Scutellaria barbata D. Don. on cultured human uterine leiomyoma cells by down-regulation of the expression of Bcl-2 protein. Phytother Res 22: 583-590, 2008.
6. Gao J, Lu WF, Dai ZJ, Lin S, Zhao Y, Li S, Zhao NN, Wang XJ, Kang HF, Ma XB, et al: Induction of apoptosis by total flavonoids from Scutellaria barbata D. Don in human hepatocarcinoma MHCC97-H cells via the mitochondrial pathway. Tumour Biol 35: 2549-2559, 2014.

7. Lin J, Chen Y, Cai Q, Wei L, Zhan Y, Shen A, Sferra TJ and Peng J: Scutellaria Barbata D Don Inhibits Colorectal Cancer Growth via Suppression of Multiple Signaling Pathways. Integr Cancer Ther 13: 240-248, 2014.

8. Wei L, Lin J, Wu G, Xu W, Li H, Hong Z and Peng J: Scutellaria barbata D. Don induces G1/S arrest via modulation of p53 and Akt pathways in human colon carcinoma cells. Oncol Rep 29: 1623-1628, 2013

9. Wei L, Lin J, Xu W, Cai Q, Shen A, Hong Z and Peng J: Scutellaria barbata D. Don inhibits tumor angiogenesis via suppression of Hedgehog pathway in a mouse model of colorectal cancer. Int J Mol Sci 13: 9419-9430, 2012.

10. Jiang Q, Li Q, Chen H, Shen A, Cai Q, Lin J and Peng J: Scutellaria barbata D. Don inhibits growth and induces apoptosis by suppressing IL-6-inducible STAT3 pathway activation in human colorectal cancer cells. Exp Ther Med 10: 1602-1608, 2015.

11. Zhang L, Cai Q, Lin J, Fang Y, Zhan Y, Shen A, Wei L, Wang L and Peng J: Chloroform fraction of Scutellaria barbata D. Don promotes apoptosis and suppresses proliferation in human colon cancer cells. Mol Med Rep 9: 701-706, 2014.

12. Bartel DP: MicroRNAs: Genomics, biogenesis, mechanism, and function. Cell 116: 281-297, 2004.

13. Esquela-Kerscher A and Slack FJ: Oncomirs - microRNAs with a role in cancer. Nat Rev Cancer 6: 259-269, 2006.

14. Calin GA and Croce CM: MicroRNA signatures in human cancers. Nat Rev Cancer 6: 857-866, 2006.

15. Calin GA, Sevignani C, Dumitru CD, Hyslop T, Noch E, Yendamuri S, Shimizu M, Rattan S, Bullrich F, Negrini M, et al: Human microRNA genes are frequently located at fragile sites and genomic regions involved in cancers. Proc Natl Acad Sci USA 101: 2999-3004, 2004.

16. Li Y, Guessous F, Zhang Y, Dipierro C, Kefas B, Johnson E, Marcinkiewicz L, Jiang J, Yang Y, Schmittgen TD, et al: MicroRNA-34a inhibits glioblastoma growth by targeting multiple oncogenes. Cancer Res 69: 7569-7576, 2009.

17. Hermeking H: The miR-34 family in cancer and apoptosis. Cell Death Differ 17: 193-199, 2010.

18. Yamakuchi M, Ferlito M and Lowenstein CJ: miR-34a repression of SIRT1 regulates apoptosis. Proc Natl Acad Sci USA 105: 13421-13426, 2008.

19. Tazawa H, Tsuchiya N, Izumiya $M$ and Nakagama H: Tumorsuppressive miR-34a induces senescence-like growth arrest through modulation of the E2F pathway in human colon cancer cells. Proc Natl Acad Sci USA 104: 15472-15477, 2007.

20. Ma Y, Bao-Han W, Lv X, Su Y, Zhao X, Yin Y, Zhang X, Zhou Z, MacNaughton WK and Wang H: MicroRNA-34a mediates the autocrine signaling of PAR2-activating proteinase and its role in colonic cancer cell proliferation. PLoS One 8: e72383, 2013.

21. Wu J, Wu G, Lv L, Ren YF, Zhang XJ, Xue YF, Li G, Lu X, Sun Z and Tang KF: MicroRNA-34a inhibits migration and invasion of colon cancer cells via targeting to Fra-1. Carcinogenesis 33: 519-528, 2012.

22. Bu P, Chen KY, Chen JH, Wang L, Walters J, Shin YJ, Goerger JP, Sun J, Witherspoon M, Rakhilin N, et al: A microRNA miR-34a-regulated bimodal switch targets Notch in colon cancer stem cells. Cell Stem Cell 12: 602-615, 2013.

23. Chi Y and Zhou D: MicroRNAs in colorectal carcinoma - from pathogenesis to therapy. J Exp Clin Cancer Res 35: 43, 2016.

24. Buriani A, Garcia-Bermejo ML, Bosisio E, Xu Q, Li H, Dong X, Simmonds MS, Carrara M, Tejedor N, Lucio-Cazana J, et al: Omic techniques in systems biology approaches to traditional Chinese medicine research: Present and future. J Ethnopharmacol 140: 535-544, 2012.

25. Shen A, Lin W, Chen Y, Liu L, Chen H, Zhuang Q, Lin J, Sferra TJ and Peng J: Pien Tze Huang inhibits metastasis of human colorectal carcinoma cells via modulation of TGF- $\beta 1 /$ ZEB/miR-200 signaling network. Int J Oncol 46: 685-690, 2015.

26. Pan L, Sheung Y, Guo W, Rong ZB and Cai ZM: Hedyotis diffusa plus Scutellaria barbata induce bladder cancer cell apoptosis by inhibiting Akt signaling pathway through downregulating miR-155 expression. Evid Based Complement Alternat Med 2016: 9174903, 2016.

27. Guo H, Lu Y, Wang J, Liu X, Keller ET, Liu Q, Zhou Q and Zhang J: Targeting the Notch signaling pathway in cancer therapeutics. Thorac Cancer 5: 473-486, 2014. 
28. Boareto M, Jolly MK, Goldman A, Pietilä M, Mani SA, Sengupta S, Ben-Jacob E, Levine $\mathrm{H}$ and Onuchic JN: NotchJagged signalling can give rise to clusters of cells exhibiting a hybrid epithelial/mesenchymal phenotype. J R Soc Interface 13: 13,2016

29. Pang RTK, Leung CON, Ye TM, Liu W, Chiu PC, Lam KK, Lee KF and Yeung WS: MicroRNA-34a suppresses invasion through downregulation of Notch1 and Jagged1 in cervical carcinoma and choriocarcinoma cells. Carcinogenesis 31: 1037-1044, 2010.

30. Ye QF, Zhang YC, Peng XQ, Long Z, Ming YZ and He LY: Silencing Notch-1 induces apoptosis and increases the chemosensitivity of prostate cancer cells to docetaxel through Bcl-2 and Bax. Oncol Lett 3: 879-884, 2012.

31. Gao F, Yao M, Shi Y, Hao J, Ren Y, Liu Q, Wang X and Duan H: Notch pathway is involved in high glucose-induced apoptosis in podocytes via Bcl-2 and p53 pathways. J Cell Biochem 114: 1029-1038, 2013

32. Zhang C, Mo R, Yin B, Zhou L, Liu Y and Fan J: Tumor suppressor microRNA-34a inhibits cell proliferation by targeting Notch1 in renal cell carcinoma. Oncol Lett 7: 1689-1694, 2014.
33. Xia J, Duan Q, Ahmad A, Bao B, Banerjee S, Shi Y, Ma J, Geng J, Chen Z, Rahman KM, et al: Genistein inhibits cell growth and induces apoptosis through up-regulation of miR-34a in pancreatic cancer cells. Curr Drug Targets 13: 1750-1756, 2012.

34. Jia H, Yang Q, Wang T, Cao Y, Jiang QY, Ma HD, Sun HW, Hou MX, Yang YP and Feng F: Rhamnetin induces sensitization of hepatocellular carcinoma cells to a small molecular kinase inhibitor or chemotherapeutic agents. Biochim Biophys Acta 1860: 1417-1430, 2016.

35. Raver-Shapira N, Marciano E, Meiri E, Spector Y, Rosenfeld N, Moskovits N, Bentwich Z and Oren M: Transcriptional activation of miR-34a contributes to p53-mediated apoptosis. Mol Cell 26: 731-743, 2007.

36. Lodygin D, Tarasov V, Epanchintsev A, Berking C, Knyazeva T, Körner H, Knyazev P, Diebold J and Hermeking H: Inactivation of miR-34a by aberrant CpG methylation in multiple types of cancer. Cell Cycle 7: 2591-2600, 2008. 